\title{
$O$ indivíduo e o coletivo: alguns desafios da Epidemiologia e da Medicina Social (*)
}

\author{
Edson Perini ${ }^{1}$ \\ Helena Heloísa Paixão² \\ Celina Maria Módena ${ }^{3}$ \\ Roberto do Nascimento Rodrigues ${ }^{4}$
}

PERINI, E. et al. , The individual and the collective - challenges in the fields of Epidemiology and Social Medicine. Interface _ Comunic, Saúde, Educ, v.5, n.8, p.101-18, 2001.

This article reviews certain fundamental Epidemiology concepts, exploring the counterpoints of their main philosophical contradictions. Thus, the conceptual interdependence between the individual and the collective is discussed, as well as the complementary nature of quantitative and qualitative approaches, the natural and social character of human existence and, finally, the collective and individual expressions of risk. Based on this analysis, the author concludes that the concept of risk harbors the potential for a revision of epidemiological practice. Without overstepping the limits that science imposes upon the production of knowledge, this revision is suggested based on the practice of the confluence of quantitative and qualitative research methods, closer to the immediate needs of individuals. As the knowledge of collective reality becomes significant to them, the likelihood of their contributing to the efficiency of Social Medical Care increases.

KEY WORDS: Epidemiology; Social Medicine; risk.

Alguns conceitos fundamentais da Epidemiologia são revisados, explorando contrapontos de suas principais contradições filosóficas. Nesse sentido, discute-se a interdependência conceitual entre o indivíduo e o coletivo, a complementaridade das abordagens quantitativas e qualitativas, o caráter natural e social da existência humana e, finalmente, as expressões coletiva e individual do risco. Da análise conclui-se que o conceito de risco traz em si potencial para uma revisão da prática epidemiológica. Sem fugir aos limites que a ciência coloca à produção do conhecimento, essa revisão é proposta a partir da prática da confluência dos métodos quantitativo e qualitativo de investigação, mais próxima das necessidades imediatas dos indivíduos. Suas chances de contribuir para tornar mais eficientes as ações da Medicina Social crescem à medida que o conhecimento da realidade coletiva ganha sentido para eles.

PALAVRAS-CHAVE: Epidemiologia; Medicina Social; risco.

\footnotetext{
* Retirado de: Perini, E.. O abandono do tratamento da tuberculose: transgredindo regras, banalizando conceitos. Belo Horizonte, 1998. Tese (Doutorado). Escola de Veterinária da Universidade Federal de Minas Gerais..

${ }^{1}$ Professor do Departamento de Farmácia Social, Faculdade de Farmácia, Universidade Federal de Minas Gerais/UFMG. <edson@farmacia.ufmg.br>

${ }^{2}$ Professora do Departamento de Odontologia Preventiva e Social, Faculdade de Odontologia, UFMG.

${ }^{3}$ Professora do Departamento de Medicina Veterinária Preventiva e Social, Escola de Veterinária, UFMG.

${ }^{4}$ Professor do Departamento de Demografia, Faculdade de Ciências Econômicas, UFMG. <beto@cedeplar.ufmg.br>
} 


\section{Introdução}

$\mathrm{O}$ artigo concentra-se no debate entre as contradições fundamentais que vivem a Medicina Social e a Epidemiologia modernas, bem como entre as opções metodológicas para a (sempre provisória) superação das mesmas. A primeira consideração introdutória diz respeito à própria distinção entre Medicina Social, um corpo de conhecimentos e ações, e métodos para adquirir conhecimentos e realizar ações referentes à atenção médica na sociedade, e Epidemiologia, uma ciência aplicada que se desenvolveu como suporte científico desse corpo de conhecimentos, buscando compreender a distribuição e os processos de determinação da saúde e da doença nas coletividades humanas (McKeown \& Lowe, 1986).

A segunda nos leva ao 'não-acaso' histórico do surgimento $e$ desenvolvimento dessas duas ciências em uma mesma época, bem como de suas ligações. Ambas nasceram da necessidade de superar pensamentos $e$ ações individualizadas que marcaram a medicina até o século XVIII. Pensar e agir sobre a doença no âmbito coletivo surgia como necessidade para superar os impasses de uma medicina que não respondia aos desafios impostos às sociedades pelas doenças infecciosas (Silva, 1985; Rosen, 1994). Embora a Medicina Social e a Epidemiologia tenham surgido em uma época de predomínio da teoria dos miasmas, a primeira teve berço revolucionário $e$ uma rica história de contribuições com as Ciências Sociais no século passado, enquanto a segunda, como ciência, se consolidou na passagem do século sob a égide da teoria dos germes, que revolucionou a ciência, mas talvez seja a maior responsável pelo solapamento teórico da primeira.

A terceira consideração refere-se ao desenvolvimento, ao escopo e ao objeto da Epidemiologia. Para se firmar (e se afirmar) como ciência da manifestação coletiva das doenças, deixou-se dominar pela "restrição filosófica" positivista, adotando uma visão (mono)causal e naturalista dos processos mórbidos, ainda que travestida em modelos multideterminísticos a alimentar o "sonho do efeito-específico à espera de ser descoberto pelo avanço científico" (Almeida Filho, 1992, p.97), e pela estatística como instrumento de construção empírica. Restringiu nossa capacidade de compreensão às manifestações do objeto, relegando os determinantes da ocorrência e distribuição das doenças a um plano talvez inacessível por essa restrição metodológica (Silva, 1985). Desenvolveu-se uma ciência filosoficamente pobre (Silva, 1985), baseada na separação sujeito $x$ objeto, expressando-se na "objetividade" da observação fragmentada da realidade, $e$ estruturada com base em dados quantitativos, uma das característica fundamentais da racionalidade científica moderna (Figueiredo, 1994).

Os valores 'humanos', culturais e sensitivos, "subjetivos" para ela, tornaram-se objetos impróprios ao conhecimento científico, ou não afeitos ao seu âmbito. Formou-se como ciência da distribuição e dos determinantes dos processos ligados à saúde no plano coletivo, mas, na busca de objetividade, afastou aspectos fundamentais da existência social e cultural humana $e$, por conseguinte, da saúde do homem. Construiu uma noção estatística do coletivo (Breilh, 1994), mera agregação de indivíduos, “...uma realidade em si" na qual "a interação e a associação de indivíduos dão lugar 
5 "Multidisciplinar Pesquisadores trabalham em paralelo ou seqüencialmente a partir de bases disciplinares específicas para tratar problema comum.

Interdisciplinar -

Pesquisadores trabalham juntos mas mantém suas bases disciplinares específicas para tratar problema comum.

Transdisciplinar Pesquisadores trabalham juntos compartilhando estruturas conceituais e construindo juntos teorias, conceitos e abordagens para tratar problema comum" (Rosenfield, 1992). a fenômenos emergentes análogos aos fatos naturais" (Barreto \& Alves, 1994). Desenvolveu seu arsenal metodológico dominada por essa noção de coletivo, fundamentada também em abordagens positivas do tempo e do espaço, e na construção probabilística do risco (Almeida Filho, 1989; 1990; 1992; Minayo, 1993).

A quarta e última consideração é o reconhecimento de que a investigação quantitativa, no processo de hegemonia da "produção de dados de inteligência para subsidiar políticas públicas em todo o Ocidente, sobretudo a partir da Segunda Guerra Mundial” (Minayo, 1994), alicerçou esse desenvolvimento de forma sólida e competente. Impulsionou-a como suporte nas áreas dos planejamentos e das avaliações das ações sanitárias, da detecção de necessidades e utilização dos serviços e tecnologias e, obviamente, nas investigações sobre os processos de determinação causal da saúde e da doença, sua obra por excelência. Transformou-a, enfim, em uma ciência com um vasto campo de investigação, porém de uma pobreza teórica quase franciscana na abordagem de seu objeto, diminuindo sua contribuição para a Medicina Social (Almeida Filho, 1992). Isso tem levado a um empobrecimento da Medicina Social, muitas vezes confundida com a própria Epidemiologia.

O suporte que oferece à Medicina Social consolidou-se nos limites do conhecimento sobre a natureza biológica da saúde/doença e nos aspectos "estruturais" da realidade social em que ocorrem, entendidos estes como aspectos mensuráveis da existência coletiva do homem (estruturas de classe, educação formal etc.). Ainda que ao longo de sua história os epidemiólogos reconheçam a dimensão simbólica da existência humana, a Epidemiologia foise tornando metodologicamente incapaz de expor tal realidade enquanto objeto de conhecimento. Hoje esta situação tem limitado a possibilidade da atuação multi, inter ou transdisciplinar ${ }^{5}$, ampliando sua abordagem no campo da pesquisa e sua colaboração na formulação de políticas e modelos teóricos mais próximos da realidade sócio-cultural das populações e, portanto, com maiores chances de provocarem mudanças reais na condição humana (Rosenfield, 1992; Nichter \& Vuckovic, 1994; Davis \& HowdenChapman, 1996).

Essas primeiras considerações têm em vista: explicitar a pretensão deste trabalho como nosso esforço para entender um pouco o que une o indivíduo e o coletivo, talvez o maior de todos os desafios da Epidemiologia; e deixar estabelecida nossa premissa de que a dimensão cultural/simbólica, característica singular do homem, permanece inacessível ao conhecimento epidemiológico em seus 'procedimentos tradicionais' de investigação. A argumentação que se segue é a vontade de contribuir para que, cada vez mais, o reconhecimento dessa inacessibilidade se transmute na admissão de que sua apreensão é fundamental para a produção de conhecimentos que servem aos mesmos propósitos, seja da Epidemiologia ou da Medicina Social. E que, por ser parte da realidade que a Epidemiologia busca como objeto, pode e deve fazer parte do conhecimento por ela produzido.

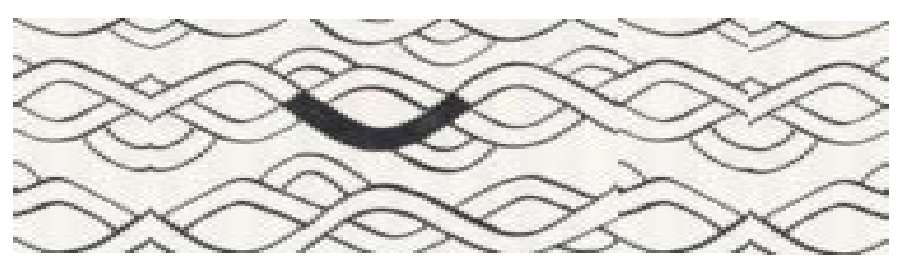

fevereiro, 2001 
O coletivo $e$ o individual

O coletivo é uma das construções fundamentais da Epidemiologia; perpassa todos os seus conceitos elementares. Para Barreto \& Alves (1994) "parece não haver dúvida da existência de uma dimensão coletiva nos seus conceitos básicos, tais como: risco, ambiente e, principalmente, população" (p.129). Porém, ao buscar nas ciências sociais o embasamento teórico e metodológico, a Epidemiologia tem-se restringido às

explicações 'morfológicas' do social”, mantendo-se incapaz de
perceber “a existência de indivíduos concretos que vivenciam, de
forma um tanto quanto particular, situações sociais que lhes são
dadas e que interpretam e fornecem significados, tanto aos seus
próprios comportamentos, quanto aos dos outros. (p.131)

É compreensível que na busca de "verdades universais" e dominada pelo "princípio escolástico Scientia non est individuorum", a "carência de uniformidade e ordem" no plano individual colocasse em xeque sua necessidade de legitimação. A Epidemiologia é produto da Modernidade, uma herança da ciência que se desenvolveu no Século XVII visando conquistar e controlar a natureza, desenvolvendo-se segundo um modelo mecanicista cujo objetivo de controle racional do Universo (Stambolovic, 1996). Na busca do coletivo, o indivíduo parece um herege.

Assim permanecendo, não conseguirá abordar a dimensão humana que ilustramos com as palavras (autênticas, ainda que jocosas) de um marinheiro bretão: "Desde que eu aprendi pelos jornais que o tabaco matava, eu tomei uma decisão: não leio mais os jornais" (Bensaïd, 1981, p.194). É preciso assumir que em toda ordem estabelecida existem "elementos de subversão", e que a heresia pode oferecer esperança (Stambolovic, 1996). Este autor nos leva a pensar que, talvez, o caminho para superar nossos impasses filosóficos e metodológicos nos esteja sendo mostrado pela chamada medicina alternativa e a busca de um entendimento holístico do homem, indivíduo e coletividade na conformação de [um] novo modelo psico-social. A "carência de uniformidade e ordem" não pode ser obstáculo ao conhecimento científico, afinal, não condena os indivíduos à inexistência. Se essa é uma característica própria das unidades, e se estas são as bases formadoras do todo, assim devem ser observadas e analisadas. Essa é a característica que as une em semelhanças e organizações, esse é o seu padrão.

O grande desafio parece ser este. Encontrar caminhos para a produção de conhecimentos que nos permitam compreender de forma menos 'reduzida' a realidade coletiva dos processos da saúde e da doença. Esta busca não pode se restringir aos limites tradicionais dos estudos: procedimentos metodológicos não são mais que posturas historicamente construídas para se atingir objetivos (leia-se, respostas a problemas científicos) que agora se quer ampliados (ou modificados, apenas?). Porém, ampliados ou modificados, ainda se colocam dentro dos limites dessa ciência, dados pela

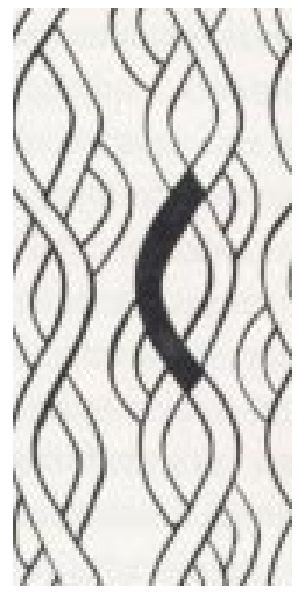


expressão coletiva dos processos. Em outras palavras, tendo o cuidado de não banalizar seus conceitos, não há razões para que a busca de novos patamares (ou novas formas, apenas?) do conhecimento epidemiológico não se faça pela transgressão de seus padrões metodológicos.

Nunca é demais lembrar que "a Epidemiologia tem limites muito específicos e, além deles, será difícil reconhecê-la como tap' (Almeida Filho, 1992, p.60), definidos pela expressão coletiva dos processos da saúdel doença dos homens. Esse autor admite que a Epidemiologia pode "dar conta da lacuna que existe entre o individual e o coletivo". Entretanto, para ele, isso deve acontecer sem se referir "ao coletivo simbolizado com que tipicamente estamos acostumados nas abordagens sociais da saúde, nem ... com a mera expressão individual, característica da clínica vulgar" (p.60). Esta segunda 'linha limítrofe' é de fácil compreensão. A expressão individual, de interesse da 'clínica vulgar', é característica e distinta do interesse da Epidemiologia. Porém, não é simples visualizar caminhos para uma abordagem mais 'dinâmica e globalizante' da expressão coletiva desvinculada de sua existência simbólica. Confunde ainda a expressão do autor de que é

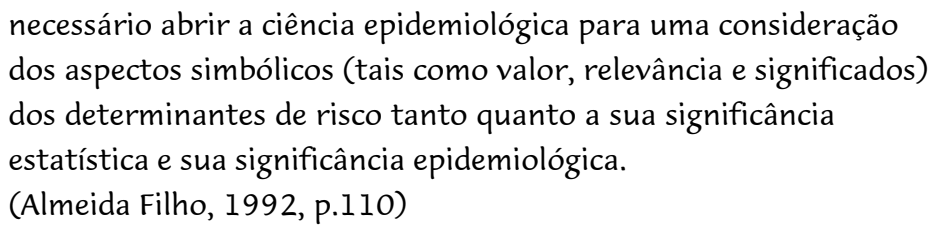

Não se referir a esse 'coletivo simbolizado' é, para nós, condenar-se à naturalização e à falta de unidade na apreensão do indivíduo e do coletivo. É permanecer na orientação reducionista que, ao longo dos anos, vem enfatizando a coleta de informações quantitativas em termos do indivíduo $e$ organizadas dentro de parâmetros científicos hermeticamente definidos, com implicações negativas na transposição dos conhecimentos produzidos pelas pesquisas em políticas de saúde. Essa postura tem limitado as aplicações a problemas de pequena escala e que evitam as principais questões das transformações estrutural e do sistema (Davis \& HowdenChapman, 1996).

É preciso beber em outras fontes para verificar que as relações sociais de produção da saúde integralizam as relações sociais mais gerais de produção e construção do self (Nichter \& Vuckovic, 1994). Nessas relações encontraremos material para uma transgressão não banalizadora dos padrões de construção do conhecimento epidemiológico, que se traduz por fugir aos processos metodológicos e às estruturas tradicionais desse conhecimento, mas mantendo-se no interior do compromisso laboriosamente desenvolvido de desvendar a existência de padrões coletivos no processo da saúde e da doença.

A Epidemiologia tradicional, como toda a medicina científica moderna, desenvolveu-se nos limites do modelo biologicista da prática clínica e, em função dele, grande parte de sua produção tem desempenhado seu papel de ciência voltada para a ação. Uma das razões pelas quais não tem 
ultrapassado esses limites é sua dificuldade de apreender o indivíduo, para o qual refluirá o conhecimento por ela produzido. Em outras palavras, ainda que seu conhecimento seja referente à dimensão coletiva da saúde e da doença, os conceitos produzidos não podem perder o referencial do nível no qual se concretizarão as ações, o indivíduo.

Toda a base filosófica e, conseqüentemente, metodológica da Epidemiologia não tem considerado que, ao deixar de considerar o indivíduo, deixa de existir o coletivo simbolizado, única fonte de identidade entre ambos. Isso não tem sido suficientemente questionado como um caminho para apreender a dinâmica do complexo processo de interações macro e micro-ambientais que caracterizam a vida dos indivíduos e grupos (Lilja \& Larsson, 1994). Em última instância, esse complexo processo é a própria realidade de seu objeto, é o ambiente onde existe o indivíduo e onde se concretizarão os processos mórbidos e as ações promovidas pelos conhecimentos produzidos por ela (e por todas as outras atividades humanas). É, portanto, o local privilegiado para exercer seu potencial transformador.

Segundo Almeida Filho (1992, p.75), "a Epidemiologia trabalha com populações ou amostras, condenada à ambição da 'lei dos grandes números"'. Resta-nos compreender o coletivo enquanto unidade/diversidade cultural $e$ o indivíduo como unidade/diversidade cultural e biológica. Uma percepção que traz perspectiva de intervenções específicas, mas que guarda dimensões não alcançadas pelos grandes números (ainda que estes nos levem a parcelas importantes de seu conhecimento). Posturas semelhantes não significam, necessariamente, fugir do campo da Epidemiologia, embora o grande desafio seja mantê-lo teoricamente e não fugir dele na prática da pesquisa. Superar esse desafio parece ser o papel dos trabalhos trans- ou interdisciplinares.

Barreto \& Alves (1994) trazem duas contradições da Epidemiologia importantes para nossas reflexões. A primeira, explícita no texto enquanto tal, nos diz que, embora se trate de uma ciência do coletivo, suas práticas médicosanitárias estão direcionadas a indivíduos, contudo tal direcionamento em nenhum momento pode ser interpretado como a síntese entre indivíduo $e$ coletividade. Esta história vem revelando "limitações e incongruências, tanto nos modelos de intervenção, quanto no próprio fundamento teórico da ciência" (p.130). A segunda, não explícita enquanto contradição no texto, nos diz que "a tentativa de dar conta do coletivo ... tem sido ... problemática. $\mathrm{Na}$ literatura epidemiológica, o coletivo é sempre referido, mas usualmente esvaziado de qualquer força explicativa" (p.134).

Esta última reflexão não pode deixar de ser pensada como a mais fundamental de todas as suas contradições. O conceito primitivo da ciência perde seu poder explicativo diante de suas posturas filosóficas e metodológicas. As razões de tais paradoxos podem ser muitas, mas certamente incluem a incapacidade de apreender o coletivo e o indivíduo como uma construção mútua. A produção de conhecimentos no plano coletivo que não inclui sua dimensão individual gera problemas na transposição e na orientação de políticas $e$ atitudes.

Não faz parte das pretensões deste trabalho assumir uma posição de intermediação conceitual entre os processos naturais e sociais, uma armadilha 
difícil de se evitar, e que adiante discutiremos. Algo que Almeida Filho (1992, p.54) classifica como "uma expressão pedante, de sentido obscuro, que entretanto tornou-se moda no discurso sanitarista das últimas duas décadas". Segundo ele

A Epidemiologia suporta o desafio de integrar o individual e o
coletivo, mas isso não inclui a pretensão de dar conta da 'interface
entre o biológico e social'. Isto porque na verdade não se pode
recortar os objetos. Um fato biológico em seres humanos é em si
social e historicamente determinado. Um projeto científico mais
conseqüente não deverá buscar o isolamento e sim a totalização.
Isso pode se dar com o recurso à Epidemiologia mas não
obrigatoriamente com o método epidemiológico. (p.54)

Como essa totalização necessária para um projeto "mais conseqüente" está além de nossa ciência contemporânea, resta-nos buscar, nos indivíduos, expressões coletivas não mensuráveis de sua existência, acreditando, pura e simplesmente, ser possível, e necessário, uma Epidemiologia capaz de produzir um conhecimento coletivo que não ignore o indivíduo e possa para ele ser transportado.

\section{Quantitativo e qualitativo}

Se hoje falamos de um objeto próprio da Epidemiologia, a doença enquanto manifestação coletiva (Silva, 1985), observada em uma perspectiva "de natureza probabilística" (Almeida Filho, 1990, p.209), e aceitamos as considerações anteriores, reconheceremos sem dificuldade que modelos "menos fragmentados" de representação da realidade são necessários para uma aproximação maior com esse "objeto". Isso porque é necessário tornar o imponderável objeto da Epidemiologia, escapando ao senso comum e embasando esse conhecimento em um sólido corpo teórico, utilizando-o

não como uma alternativa ideológica às abordagens quantitativas, mas a aprofundar o caráter social $e$ as dificuldades de construção do conhecimento que o apreende de forma parcial e inacabada. (Minayo, 1993, p12)

Cabe aqui um retorno a Almeida Filho (1992, p.100), partidário da idéia de que

contrariamente ao que se encontra semi-explícito nos manuais da área ... não se trata de um objeto probabilístico porque a essência do objeto epidemiológico é na verdade o que sobra da probabilidade, aquilo que os modelos probabilísticos não são capazes de dar conta.

Uma reflexão interessante sobre a existência do epidemiólogo decorre disso: fosse a determinação epidemiológica confundida com a

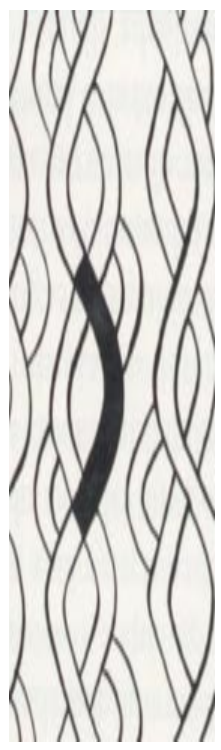

107 
probabilística, a Epidemiologia perderia sua razão de existir e os estatísticos seriam os senhores absolutos das explicações. Nesse "resto" da probabilidade encontramos material para a Epidemiologia, quantificável em sua experiência concreta, mas imponderável em sua essência ${ }^{6}$, e nem por isso arredio ao conhecimento científico.

Um caminho para a construção desse conhecimento é a apreensão dos significados (Minayo, 1993), caminho para a interação entre a Epidemiologia "tradicional" e a pesquisa qualitativa, buscando perceber a saúde/doença por novos prismas, e melhor servindo aos interesses da Medicina Social. Significa, sem trocadilho, melhor servir a um projeto de maior qualidade de vida, facilitando e ampliando a compreensão da saúde/doença $e$ as ações (e reações) dirigidas por esse conhecimento.

Há uma bem discutida complementaridade (Minayo, 1994) entre as abordagens quantitativa e qualitativa do objeto da Epidemiologia, postura teórico-metodológica que pode trazer profundas implicações para a Medicina Social (Gonçalves, 1986). Assistimos à influência positivista nos levar a um conhecimento científico e a uma prática em que o processo saúde/doença é percebido enquanto fenômeno biológico, com profundidade e em uma perspectiva mecanicista (Silva, 1985; Queiróz, 1986; Figueiredo, 1994). Nessa história, a dimensão social se constitui como um conjunto de variáveis que qualificam e classificam esse fenômeno, participando da análise causal nunca além dos aspectos estruturais, "morfológicos" (Minayo, 1994, citando Gurvitch), da existência social do homem. Uma "região mais visível dos fenômenos" sociais que

...Gurvitch denomina 'morfológica, ecológica, concreta' e explica que tal dimensão admite adequada expressão através de equações, médias, gráficos e procedimentos estatísticos. A partir daí, adverte Gurvitch, torna-se difícil trabalhar com dados numéricos, uma vez que se encaminha para um universo de significados, motivos, aspirações, atitudes, crenças e valores. Esse conjunto de dados 'qualitativos' necessita de um referencial de coleta e de interpretação de outra natureza. Mas, chama atenção o autor, essas camadas são interdependentes, interagem e não podem ser pensadas de forma dicotômica. (Minayo, 1994, p.27)

A essa complementaridade se refere Almeida Filho (1992, p.58):

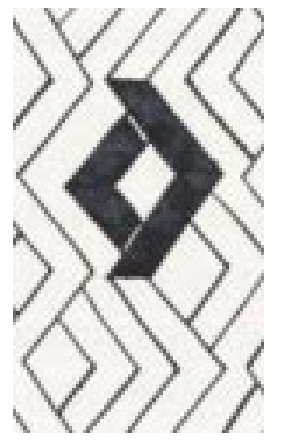

... acredito que há várias, e criativas, formas de integração das técnicas qualitativas na investigação epidemiológica, dentre as quais_destaco: a) abordagens mais aprofundadas podem fornecer elementos para validação de instrumentos de pesquisa; b) técnicas qualitativas podem tornar-se fontes de hipóteses e modelos teóricos; c) abordagens qualitativas podem ajudar a compor desenhos mistos de investigação epidemiológica, tais que superem o distanciamento do real inerente aos desenhos mais estruturados; d) abordagens desse tipo podem finalmente auxiliar na interpretação de resultados epidemiológicos, como por exemplo ilustrando associações mais complexas através de histórias de caso.
${ }^{6}$ Assume-se aqui que o adoecer humano é, em sua essência, imponderável, porque simbólico, porém quantificável em sua existência concreta, em suas manifestações clínica e coletiva. 
O grifo que assumimos chama atenção para a existência sugerida de outras formas de integração metodológica. No entanto, esta não é a principal questão, mas a real potencialidade de a abordagem qualitativa produzir "conhecimento epidemiológico", válido e reconhecido como tal, ainda que não validado por uma significação estatística dos resultados (Gonçalves, 1986).

Reflexo da histórica "luta do homem contra a natureza", a percepção dos indivíduos e grupos sociais, sobre sua saúde ou suas doenças tem sido alijada do saber médico como algo a ser vencido, num processo de afirmação etnocêntrica do sistema médico: fora do conhecimento oficial, o que existe é erro e ignorância (Minayo, 1994). A conseqüência foi a valorização excessiva da tecnologia médica como solução potencial para todos os males e do papel dos profissionais de saúde como agentes da ação (Minayo, 1993; Perini, 1997).

Essa história do conhecimento médico foi construída no interior da dimensão cultural/simbólica do homem, o que inclui sua saúde e suas doenças, embora busque negá-la em um modelo idealizado de causa única necessária e suficiente. Construir um conhecimento englobando esta dimensão, baseado na busca dos significados pela pesquisa qualitativa, poderá ter para a Epidemiologia duas implicações fundamentais: maior $e$ melhor compreensão de seu objeto - doentes em população - ao transcender sua dimensão probabilística $e$ a separação objeto $x$ observador como condições de objetividade, trazendo à tona a dimensão cultural como condição de existência de ambos, e relativização de seus conceitos fundamentais - o tempo, o espaço, o coletivo e o risco - a partir da percepção do indivíduo, locus único onde se realiza a "tríplice abordagem" do fato social, onde se faz "coincidir a dimensão propriamente sociológica com seus múltiplos aspectos sincrônicos; a dimensão histórica, ou diacrônica; e, finalmente, a dimensão fisio-patológica" (Lévi-Strauss, 1974, p.14, grifos nossos).

Embora a estrada seja longa, "há flores no caminho"! Parece-nos apenas necessário uma ciência do homem que, sem medir o homem, entenda um homem consciente de sua própria existência e que nada precisa medir em si para saber que

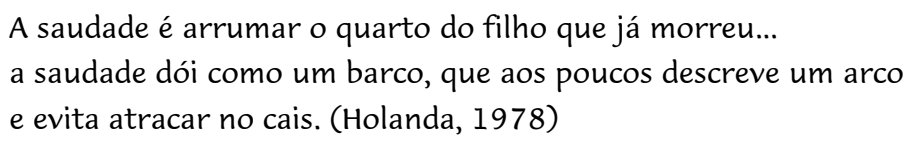

Natural e social

Essa maior aproximação com o objeto e a relativização de conceitos poderão, por sua vez, ter conseqüências teóricas e práticas importantes. Podem nos ajudar a superar os limites impostos à Epidemiologia pela Tríade Ecológica $e$ sua extensão, a História Natural das Doenças (Leavell \& Clark, 1978). Embora inegáveis, os avanços na reformulação da noção de causalidade ou na própria formação dos conceitos de risco e fatores de risco que hoje fundamentam a Epidemiologia dificultam uma abordagem menos 
fragmentária e compartimentalizada do processo saúde-doença. São modelos reducionistas ${ }^{7}$, desenvolvidos para a (e desenvolventes da) linguagem das variáveis e de suas articulações internas em processos quantificáveis. Neles, a sociedade existe como um somatório amorfo de indivíduos; estes são pensados fora do coletivo que constróem, representando apenas e sempre "o susceptível", aquele que é exposto ou não, aquele que adoece ou não, $e$ nunca aquele que pensa e tem seu próprio significado para sua situação de susceptível no lugar que constrói; o lugar (o espaço) permanece como um conjunto de limites ahistóricos, não assumindo seu real valor explicativo de ambiente onde ocorrem os processos naturais e sociais da relação homem $x$ agente; o "agente" mantém-se como uma entidade cuja relação com o homem se limita aos seus aspectos naturais - físicos, químicos e biológicos; e o tempo se faz representar tão somente pela noção cronológica do observador ${ }^{8}$.

As conseqüências desses modelos na prática epidemiológica e na organização institucional do setor saúde, e suas aliadas indústrias, são bem conhecidas (Quadra, 1983; Lexchin, 1988). No entanto, interessa-nos, no momento, a prática da pesquisa epidemiológica, em relação à qual devemos considerar:

Em princípio, o determinante epidemiológico por definição pode ser tomado como parte do objeto das ciências sociais, ao nível das relações sociais. Fatores de exposição ou determinantes de risco, por mais forte que seja sua vinculação biológica, são sempre considerados tendo como referência a formação do delimitador do objeto epidemiológico, populações, coletivos humanos, grupos submetidos a relações interpessoais, exercendo 'modos de vida' (ou sofrendo 'condições de vida'), determinados pelas relações sociais de produção. Na pesquisa epidemiológica, idade será sempre mais do que número de anos vividos, sexo mais que definição genital, dieta mais que ingesta alimentar, herança mais que genética, exposição mais que efeitos químicos, lugar mais que geografia e tempo sempre mais que história individual. Trata-se de uma outra forma de considerar o inescapável caráter social da ciência epidemiológica. (Almeida Filho, 1992, p.56-7)

Ainda que tais parâmetros sejam matematizados na pesquisa epidemiológica, $e$ analisados em uma perspectiva reducionista, permanecem implícitas essas suas dimensões, dado que as relações de determinação epidemiológica expandem-se do nível das probabilidades para a determinação social dos processos. Neste nível, a Epidemiologia encontrará a "intenção" e os "sentidos", os quais, mesmo quando quantificáveis em suas manifestações, permanecem imponderáveis em suas essências.

Vimos que a Epidemiologia tem por objeto as manifestações coletivas dos processos da saúde e da doença nos homens, em uma perspectiva "de natureza probabilística" (Almeida Filho, 1990), ainda que, como admite esse autor, o nível das determinações que compõem o objeto da Epidemiologia possa "ser tomado como parte do objeto das Ciências Sociais", referindo-se à
7 "Expor a ideologia reducionista tornou-se muito complicado, porque a maneira reducionista de pensar passou a ser tão dominante nos anos recentes, que se transformou no que se pode descrever como a ideologia da própria ciência... A oposição ao reducionismo provém, primariamente, do materialismo dialético que argumenta que, embora os fatos de cada nível hierárquico representado pelas diferentes ciências devam corresponder a fatos em níveis inferiores ou superiores, eles não podem ser reduzidos, pela aplicação de leis ou relações causais, aos níveis inferiores: a Biologia não pode ser invocada para explicar a Sociologia, ao contrário, há uma interação dialética entre elas"(Rose \& Rose, citados por Quadra, 1983).

8 Sugerimos a leitura de Quadra (1983), como uma análise mais profunda sobre o modelo da História Natural da Doença, de Silva (1985), como exemplo de abordagem de uma doença dentro de uma perspectiva de transcendência da naturalização dos processos e, de Almeida Filho (1992) e Barreto E Alves (1994), como abordagens críticas das limitações da

Epidemiologia contemporânea para

lidar com seu objeto de forma mais

abrangente, leia-se, menos naturalizada ou, reduzida. Há também alguns trabalhos que procuram desenvolver o conceito de tempo além do usualmente utilizado na prática da pesquisa empírica (Pinto, 1973, Elias 1994, Sevalho, 1996 e 1997) 
'sobra da probabilidade', aquela parcela das relações não passíveis de atribuição às regras do acaso. Vimos, também, que seu desenvolvimento se fez com a hegemonia de uma prática reducionista de investigação e de influências sobre as ações médicas e organizações institucionais, embora hoje a palavra positivismo tenha assumido uma conotação injuriosa para a maioria dos epidemiologistas (Almeida Filho, 1992).

Mesmo permanecendo dúvidas a esclarecer, falamos da Epidemiologia como uma ciência que traz a perspectiva de abordagens que dêem conta da lacuna entre o individual e o coletivo (Almeida Filho, 1992), ainda que esse autor não "autorize" uma abordagem do "coletivo simbolizado", restrição que classificamos como uma condenação à permanência do atrelamento da prática epidemiológica ao reducionismo naturalista que a tem caracterizado. Por fim, discutimos um pouco as potenciais formas de colaboração na busca do "qualitativo" para o conhecimento epidemiológico, ou mesmo de sua potencial capacidade de produção de conhecimento.

Antes de passarmos para uma discussão do risco, paradigma central da Epidemiologia (Almeida Filho, 1992; Barreto \& Alves, 1994), que implícita ou explicitamente governa todo o discurso, fecharemos as discussões que vêm se arrastando reafirmando convicções sobre os princípios fundamentais da explicação epidemiológica.

Se dividirmos os processos de determinação da saúde/doença dos homens em dois níveis, natural e social, encontraremos respostas para nossas perguntas epidemiológicas na coexistência necessária de ambos, em um processo mútuo de determinações. No "mundo natural", que precede na história o social e onde são concretizados os processos, encontraremos a determinação probabilística, aquela regida pelo acaso e que governa nossa atual percepção epidemiológica de risco (uma percepção, portanto, naturalizada do fenômeno, e que não deixa de ser real por isso, razão pela qual não vemos nisso uma conotação pejorativa para a prática científica positivista). No "mundo social" encontraremos, por sua vez, a "intencionalidade", o que nos deixa dúvidas sobre o espaço para um raciocínio probabilístico neste nível de explicações. Isso significa outra dimensão dos processos, os quais necessitam de outras formas de investigação e expressão. Onde reina a intenção, o jogo de probabilidades é submetido e perde poder explicativo (razão pela qual entendemos o caráter pejorativo da prática científica positivista como suporte único de orientação para nossas ações).

Assim colocado, cremos que o objeto da Epidemiologia não se refere apenas ao que sobra da probabilidade, mas, incluindo esse universo (probabilístico, natural ou mesmo naturalizado) de determinação, transcende-o na busca de compreensão das leis da ordem social dos processos, dado que não há como, no mundo real, imaginá-los separados. A questão não é pois, mediá-los, mas compreendê-los cada um em suas potencialidades, cada um como parte do outro.

Em nossa prática científica, ao reduzirmos o social a variáveis isoladas, como partes componentes de um modelo fragmentado da realidade, retiramos a possibilidade de compreender o risco para além de sua dimensão natural ou naturalizada - modelos assim construídos dirigem nossa percepção para uma dimensão probabilística. Ora, se o homem contém em si essas duas dimensões, 
o risco probabilístico tende a ser interpretado por ele como uma realidade governada por sua existência natural, não simbólica, coletiva mas natural (ou naturalizada em sua interpretação). Nessa dimensão, talvez encontraremos nossas explicações para os comportamentos do homem nos "instintos", dado que a percepção individual do risco é inerente a todo $e$ qualquer ser vivo, ainda que, no caso dos homens, informada, e assim transformada em níveis bastante distintos.

No nível social, não há como compreender uma dimensão não simbolizada do risco, carregado de interpretações, significados singulares (individuais) de sua existência e experiência probabilística. Essa existência simbólica singular expressa-se coletivamente na formação cultural do meio em que se insere, e que transforma os instintos, fornecendo material para compreender não o comportamento do homem, mas a atitude humana. Não apenas a doença do homem, mas a doença humana! O objeto da Epidemiologia inclui não só a doença do homem, mas também a doença humana, ambas em suas expressões coletivas, naturalizadas ou simbolizadas.

Mas, nossa pretensão não se refere a uma intermediação entre o natural e o social. Busca um entendimento dos processos de saúde/doença que considere ambos os níveis de determinação, ou que admita a validade das regras advindas do conhecimento produzido pelas determinações do nível natural, ou mesmo do nível social, porém em uma perspectiva estrutural, $e$ dê conta de explicar suas implicações/relações com a existência simbólica do homem. Em outras palavras, a questão não é a existência ou não de uma intermediação conceitual, mas a consciência de diferentes níveis de explicação dos fenômenos, porque simplesmente eles assim se compõem, $e$ nem um, nem outro, domina a verdade maior ou absoluta. Apenas alcançam diferentes níveis por meio de estruturas conceituais e metodológicas diferentes e específicas.

Enfim, trata-se de buscar, na ciência, reconhecer que:

Belezas, dores e alegrias passam sem um som

Eu vejo o homem velho rindo numa curva do caminho de Hebron

E a seu olhar tudo o que é cor muda de tom.

(Veloso, 1984)

\section{Risco coletivo e risco individual}

A noção de risco, ao lado da (e conexa à) noção de coletivo é uma das grandes contribuições da Epidemiologia para as ciências da saúde (Almeida Filho, 1990; Barreto \& Alves, 1994). Expressa-se como elemento fundamental da noção contemporânea de causa dos processos saúde/doença e do discernimento entre causas necessárias e suficientes, estas últimas entendidas como condições associadas à existência das primeiras, as quais se confundem com a própria noção de agentes específicos. Na noção de causas suficientes encontraremos os aspectos estruturais ("morfológicos") da organização social. O conceito probabilístico de risco permitiu o progresso de investigações baseadas na exposição/não-exposição a fatores possivelmente associados a eventos ligados à saúde/doença. $\mathrm{O}$ 
estabelecimento da associação causal passa então a ser função de maior probabilidade de acontecimento desses "eventos" quando associados a "fatores", considerados então como "fatores de risco". Esta é, em suma, a idéia epidemiológica de risco, matematicamente expressa como o número de acontecimentos em relação ao total de acontecimentos possíveis (incidência, mortalidade). Permite medir a probabilidade de "doenças" ou "mortes" em uma coletividade, em função da experiência passada e guardadas as mesmas condições. Resume a perspectiva epidemiológica moderna da dinâmica do processo saúde/doença, permitindo acompanhar os fenômenos de forma representativa em termos estatísticos, e estabelecer parâmetros para as inferências e atividades racionalizadoras do diagnóstico de necessidades, de planejamentos e avaliações em Medicina Social (Waters, 1979).

Almeida Filho (1992) questiona, responde, e adverte:

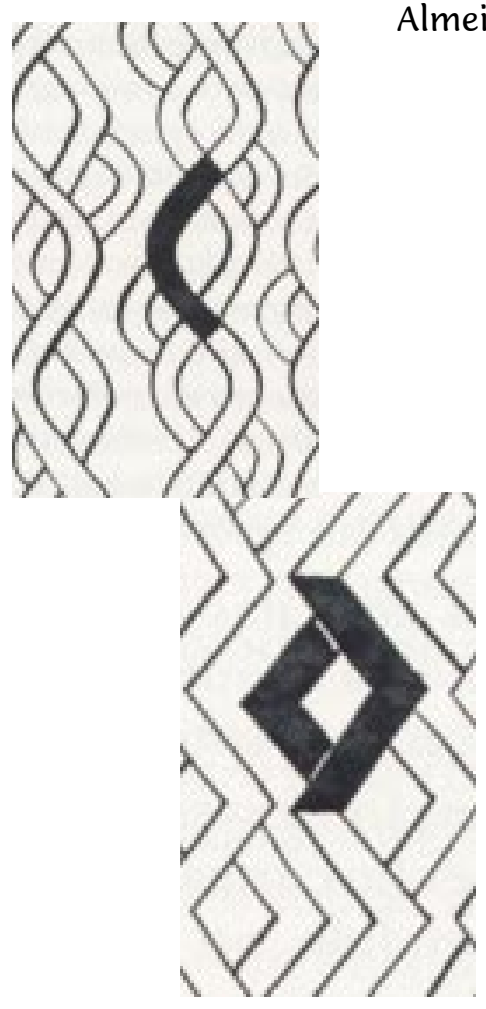

E onde se situa o risco no discurso epidemiológico? Para além e para fora do sujeito, localizado numa origem ficcional, o risco está situado no âmbito da população, produzido nos (ou atribuídos aos) coletivos humanos. Risco é enfim uma propriedade das populações e a sua referência legítima será exclusivamente coletiva (...) risco em Epidemiologia equivale a efeito, probabilidade de ocorrência de patologia em uma dada população, expresso pelo indicador paradigmático de incidência. (p.133-35)

Um parâmetro de risco pode ser legitimamente aplicado a um grupo populacional, num processo de generalização de amostra para população, com um grau mensurável de certeza. No campo clínico, a sua aplicação com uma função digamos preditiva, diagnóstica ou prognóstica, enfrenta problemas lógicos ... Será possível somente se tratarmos o paciente como um elemento de um dado conjunto e não como um indivíduo. Mas se assim procedermos, isso representará uma inevitável ruptura com o paradigma da Clínica. Trata-se em minha opinião de uma importante advertência, dirigida contra qualquer proposta de adoção de determinantes com efeitos individualizados, a qualquer nível de singularidade. (p.59)

Nessa mesma obra, o autor argumenta que "na medida em que o objeto da Epidemiologia [coletivo] não tem qualquer parentesco formal com o objeto da Clínica [individual]", não é válido, e constitui-se uma "séria distorção" (p.139), referir-se a um risco individual cujo sentido é, claramente, uma redução da construção teórica (e mesmo empírica) do risco epidemiológico.

Reflexões de Barreto \& Alves (1994) nos dizem que o desenvolvimento da Epidemiologia por meio de métodos quantitativos teve como conseqüência a limitação da "condição de risco a uma ordem de natureza métrica", reduzindo seu significado "aos fenômenos que podem ser mensurados", tornando "difícil, nessa estratégia, trabalhar com o universo de significados, motivos, aspirações, atitudes, valores e crenças que 
constituem aspectos essenciais da coletividade humana" (p.133).

Essa construção não nos permite alcançar uma (real?) dimensão individual do risco e podemos pensar nas dificuldades que nos traz para apreender os significados como "aspectos essenciais da coletividade humana". Porém, como o próprio Almeida Filho (1992, p.125) admite, não podemos pensar em uma apropriação exclusiva do "sentido epidemiológico do termo". A percepção cultural/simbólica do significado que assume para os indivíduos, o que, em última instância, governa as relações individuais para com os então definidos "fatores ou comportamentos de risco", tem estado alijada do objeto da Epidemiologia. Sobre esta relativização dos conceitos fundamentais da Epidemiologia nos referimos anteriormente. Não há como retornar para o nível individual a construção teórica do risco. Sua utilidade coletiva é inquestionável, porém sua transposição para o universo individual tem gerado distorções e incompreensões no perceber/proceder das pessoas (Bensaïd, 1983), "doutas" ou "comuns".

No intrincado processo em que reside a saúde e a doença, o "social", interpretado como um mero conjunto de variáveis independentes, constitutivas de um (parcial) processo unidirecional de determinação (i.e., o social "determina" a doença), tem se transformado em um conceito vazio de significado para o indivíduo, local concreto do processo. Ele, o social, não se apresenta como algo definidor das e definido pelas inter-relações nas condições de existência de cada um dos elementos do modelo - hospedeiro, agente e meio ambiente; é apenas mais um conjunto de variáveis, vazio de "qualquer força explicativa", como nos foi dito por Barreto \& Alves (1994, p.134).

Parece resumir-se nisso o porquê de uma dimensão única (a probabilística) para o conceito de risco: o modelo se reduz a um conjunto de conceitos naturalizados, cujas determinações se apresentam probabilísticas e podem ser pensadas, e medidas, enquanto associações estatísticas.

Verdadeiras, porém não únicas. Como procuramos esclarecer anteriormente, em parcial discordância com Almeida Filho (1992) e tendendo para as idéias de Breilh (1988), esst dimensão faz, também, parte do objeto da Epidemiologia. Porém, no universo de determinações não probabilísticas que constitui esse objeto, encontraremos a dimensão simbólica, essência da existência humana, na qual reside a intenção e a probabilidade perde seu poder de explicação; um material sobre o qual pode-se construir um conhecimento que suporta a transposição dos significados entre os níveis coletivo e individual.

É preciso, pois, estabelecer e especificar a existência de duas coisas distintas e até então isoladas em dimensões diferentes do conhecimento. Risco "probabilidade" é produto histórico do conhecimento epidemiológico, fruto da dimensão natural, ou naturalizada, do processo saúde/doença, e a tradução desta probabilidade no plano individual é uma falácia, ainda que pensemos apenas num "ser" natural, e não num "ser" simbólico. No entanto, há outra dimensão do risco a ser buscada pela ciência: diz respeito a fenômenos não mensuráveis, que nos indivíduos se manifestam como opções diante das conjunções que a vida (natureza e sociedade) lhes coloca diante, $e$ que trazem à tona um universo de significados, motivos, aspirações,

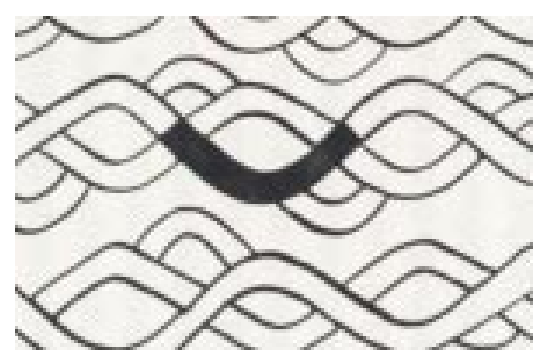




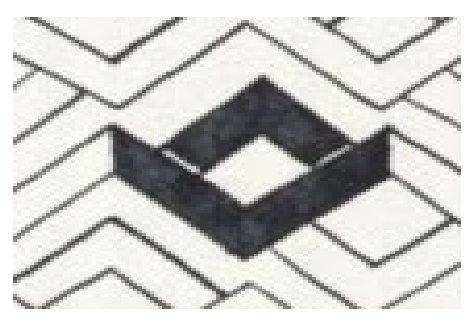

${ }^{9}$ Eficiente refere-se a uma relação custobenefício favorável eficaz refere-se a ser possuidora de

capacidade resolutiva (Breilh, 1988:46). atitudes, valores e crenças (Barreto \& Alves, 1994), expressão maior dessa realidade que constitui a essência da existência coletiva humana. Em termos dos indivíduos, atores e autores da vida, correr o risco é a concretização de uma opção - risco é opção. Um ato de vontade (Gonçalves, 1986), característica de um ser "intencional” (Minayo, 1993), regido pelos diferentes "significados" que o tempo, o espaço $e$ as relações intra $e$ inter-pessoais adquirem para ele e para os grupos sociais aos quais pertence. Esse homemopção

$$
\begin{aligned}
& \text { humaniza (altera) a natureza e altera-se a si mesmo (processo de } \\
& \text { mútua transformação permanente); desenvolve o raciocínio, tem } \\
& \text { ação intencional e planejada; produz artefatos, instrumentos, } \\
& \text { conhecimentos (senso comum, científico, filosófico, artístico, } \\
& \text { teológico). (Ruffino Netto, 1994, p.13) }
\end{aligned}
$$

Sua capacidade de opção reside no conhecimento que produz, na regra que estabelece a partir desse conhecimento, assim como na transgressão a essa regra. Uma opção significa, enfim, "liberdade", indefinível, imponderável, mas real a cada indivíduo ou grupo:

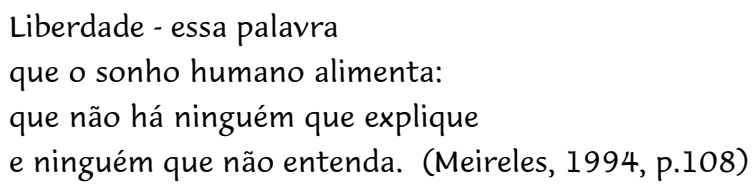

Essa dimensão não tem sido explorada pela Epidemiologia em todas as suas potencialidades. Talvez seja, realmente, universo exótico para ela. Voltando a Almeida Filho (1992, p.60), há coisas que "a ciência epidemiológica não pode dar conta", e essa dúvida mostra-se um desafio fascinante e traz a complementaridade entre essas dimensões, que, se prescindível para uma Epidemiologia de orientação "clínica", ou "tradicional", ou quaisquer correntes que buscam uma preservação metodológica e uma orientação para a dimensão natural, ou naturalizada, do processo saúde/doença, é absolutamente imprescindível para uma Epidemiologia que procura a expansão e/ou revisão metodológica e de seu objeto. Porque não dizer, que procura transgredir limites historicamente construídos. Uma Epidemiologia que busca superar suas dificuldades de abordagem do social, que busca o movimento do objeto (Breilh, 1994).

No entanto, qualquer corrente da Epidemiologia trabalha com conhecimentos muito próximos da ação, ou para ela dirigidos, caracterizandoa como uma ciência aplicada. Desta forma, a complementaridade entre diferentes dimensões da percepção do risco se torna imprescindível para as ações preconizadas pelo conhecimento produzido, pois estas ocorrem sempre num ambiente sócio-cultural dado, e se concretizam no locus onde é possível a "tríplice abordagem" de que nos fala Lévi-Strauss (1974). Aí, ação e saber serão sempre re-interpretados à luz dos significados que assumem para indivíduos e grupos, caminho para que os conhecimentos possam se traduzir em políticas de saúde eficientes ${ }^{9}$, não necessariamente construídas sobre 
vitoriosos e vencidos, culpados ou inocentes, mas apenas com indivíduos copartícipes de um mesmo sonho, ou de sonhos diversos; com indivíduos que sonham.

Vemos que o

risco percebido é um conceito multidimensional ao qual podem ser dados diferentes significados. É necessário distinguir entre riscos necessários e desnecessários e definir a decision situation e a decision option em detalhes para se ter uma medida confiável dos riscos percebidos por uma pessoa. (Lilja \& Larsson, 1994, p.1666)

Necessário pois, para a compreensão das análises epidemiológicas, distinguir diferentes dimensões de risco. Se quisermos compreender melhor, ou em outros patamares, a complexidade que envolve o processo saúde/doença nos homens, não podemos nos ater apenas à idéia de um risco epidemiológico, em sua acepção tradicional (traduzido como risco coletivo, probabilístico), mas também buscar compreender um risco que, para preservarmos os conceitos, seria conveniente nos referirmos a ele como um risco nãoepidemiológico (traduzido como risco individual, ou mesmo coletivo, porém simbólico), dimensões essas mutuamente dependentes, partícipes de um mesmo universo que a Epidemiologia procura traduzir como seu objeto.

\section{Conclusão}

O conceito de risco, hoje um dos problemas centrais da Epidemiologia, tem sua interpretação em termos probabilísticos, mas sua aplicação a situações individuais é falaciosa. Porém, sua concreção se dá no plano individual $e$ neste plano tem sua própria interpretação, não necessariamente concordante com a epidemiológica. Os conceitos desenvolvidos pela Epidemiologia, e mesmo as representações sociais dos epidemiólogos (afinal, são também humanos) sobre o coletivo e sobre o risco, são interpretações sobre a realidade observada do ponto de vista coletivo e dirigem uma postura da ciência epidemiológica (e dos epidemiólogos) não necessariamente condizente com as representações sociais dos indivíduos e grupos populacionais não ligados às ciências. Tampouco são tais conceitos assumidos no plano desses indivíduos de forma não conflitiva, ainda que não os questionem enquanto verdades. Neste particular, a noção de risco pode ter um papel interessante no desafio de buscar novos caminhos para a revisão do conhecimento epidemiológico, pois envolve uma vivência íntima dos indivíduos e seus conflitos entre o perigo e o prazer, entre a aceitação $e$ a transgressão das regras que o conhecimento científico nos permite elaborar. À medida que o conhecimento da realidade coletiva ganha sentido para eles, aumentam as chances de que venham a contribuir para tornar mais eficientes as ações da Medicina Social. Nesse sentido, a confluência das posturas adotadas nas investigações quantitativas e qualitativas apresentase como uma opção para que mudanças na prática epidemiológica se façam no interior dos limites que a ciência coloca à racionalidade humana, porém com a produção de conhecimentos capazes de adquirir sentido para as 
necessidades imediatas dos indivíduos. Na confluência dos métodos (Samaja, 1992) reside, assim, uma esperança de que a Epidemiologia assuma de forma mais eficiente sua história de contribuições para com as ações da Medicina Social.

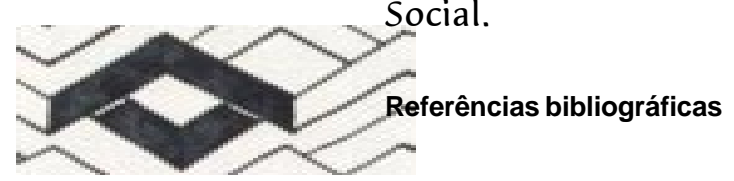

ALMEIDA FILHO, N. Epidemiologia sem números: uma introdução à ciência epidemiológica. Rio de Janeiro: Campus, 1989.

ALMEIDA FILHO, N. O problema do objeto de conhecimento na epidemiologia. In: COSTA, D.C. Epidemiologia: teoria e objeto. São Paulo: Hucitec, 1990. p. 203-20.

ALMEIDA FILHO, N. A clínica e a epidemiologia. Salvador: APCE, 1992.

BARRETO, M. L.; ALVES, P. C. O Coletivo versus individual na epidemiologia: contradição ou síntese? In: COSTA, M. F. L; SOUZA, R. P. (Orgs.) Qualidade de vida: compromisso histórico da epidemiologia. Belo Horizonte: Coopmed, 1994. p.129-36.

BENSAÏD, N. La Lumière médicale: les illusions de la prévention. Paris: Editions du Seuil, 1981. BREILH, J. Epidemiologia, economia, medicina y política. 2.ed. México: Fontamara, 1988. BREILH, J. Dialéctica de lo coletivo en epidemiologia. In: COSTA, M. F. L; SOUZA, R. P. (Orgs.)

Qualidade de vida: compromisso histórico da epidemiologia. Belo Horizonte: Coopmed, 1994. p.13545.

DAVIS, P., HOWDEN-CHAPMAN, P. Translating research findings into health policy. Soc. Science Med., v.43, n.5, p.865-872, 1996.

ELIAS, N. Time: an essay. Oxford: Blackwell, 1994.

ENGELS, F. Dialectica da natureza. Lisboa: Editorial Presença, 1974. Apud CINDRA, J.L. Friedrich Engels, a ciência, o homem e a natureza. Princípios, v.38, p.75-78, 1995.

FIGUEIREDO, A. M. A Constituição profissional da medicina homeopática na interação com a medicina alopática. Belo Horizonte, 1994. Dissertação (Mestrado). Faculdade de Filosofia e Ciências Humanas, UFMG.

GONÇALVES, R. B. M. Tecnologia e organização social das práticas de saúde: características tecnológicas do processo de trabalho na rede estadual dos Centros de Saúde de São Paulo. São Paulo, 1986. Tese (Doutorado). Faculdade de Saúde Pública, USP.

GONRING, J. I. A água dos dias e o curso do rio. São Paulo: Massao Ohno, 1991.

HOLANDA, F. B. Pedaço de mim. In: Chico Buarque: letra e música 2. 6.ed. Rio de Janeiro: Companhia das Letras, 1989. p.100.

LEAVELL, H., CLARK, E.G. Medicina preventiva. São Paulo: Mcgraw-Hill, 1978.

LÉVI-STRAUSS, C. A obra de Marcel Mauss. In: Marcel Mauss (Coleção Sociologia e Antropologia, v.2). São Paulo: EPU, 1974. p.1-48.

LEXCHIN, J. The medical profession and the pharmaceutical industry: an unhealthy alliance. Intern. Journal Health Serv., v.18, n.4, p.603-616, 1988.

LILJA, J.; LARSSON, S. Social pharmacology: unresolved critical issues. Intern. Journal Addictions, V.29, n.13, p.1647-1737, 1994.

McKEOWN, T.; LOWE, C.R. Introducción a la Medicina Social. 3.ed. México: Siglo Veintiuno, 1986.

MEIRELES, C. Romanceiro da inconfidência. 7.ed. Rio de Janeiro: Nova Fronteira, 1994. (Romance XXIV ou Da Bandeira da Inconfidência).

MINAYO, M.C.S. O desafio do conhecimento: pesquisa qualitativa em saúde. 2.ed. São Paulo: Hucitec, 1993.

MINAYO, M.C.S. Quantitativo e qualitativo em indicadores de saúde: revendo conceitos. In: COSTA, M. F. L; SOUZA, R. P. (Orgs.) Qualidade de vida: compromisso histórico da epidemiologia. Belo

fevereiro, 2001 
Horizonte: Coopmed, 1994. p.25-33.

NICHTER, M.; VUCKOVIC, N. Agenda for an anthropology of pharmaceutical practice. Soc. Science

Med., v.39, n.11, p.1509-1525, 1994.

PERINI, E. A Questão do farmacêutico: remédio ou discurso. In: BONFIM, J.R.A., MERCUCCI, V.L. A

construção da política de medicamentos. São Paulo: Hucitec/Sobravime, 1997. p.323-34.

PINTO, A.V. EI pensamiento crítico en demografia. Santiago: CELADE, 1973.

QUADRA, A.A.F. Viver é resistir. A história natural da doença. Rio de Janeiro: Achiamé, 1983.

QUEIRÓZ, M.S. O paradigma mecanicista da medicina ocidental moderna: uma perspectiva antropológica.

Rev. Saúde Púb., v.20, n.4, p.309-317, 1986.

ROSEN, G. Uma história da Saúde Pública. São Paulo: Unesp, 1994.

ROSENFIELD, P.L. The potential of transdisciplinary research for sustaining and extending linkages

between the health and social sciences. Soc. Science Med., v.35, n.11, p.1343-1357, 1992.

RUFFINO NETTO, A. Qualidade de vida: compromisso histórico da epidemiologia. In: COSTA, M. F. L.;

SOUSA, R. P. (Orgs.) Qualidade de vida: compromisso histórico da epidemiologia. Belo Horizonte:

Coopmed, 1994. p.5-24.

SAMAJA, J. La combinacion de metodos: pasos para una comprension dilectica del trabajo interdisciplinario.

Educación Médica y Salud, v.26, n.1, p.4-34, 1992.

SEVALHO, G. Velocidade/aceleração temporal e infecções emergentes: epidemiologia e tempo social.

História, Ciências, Saúde, v.3, n.2, p.217-236, 1996.

SEVALHO, G. Tempos históricos, tempos físicos, tempos epidemiológicos: prováveis contribuições de Fernand Braudel e llya Prigogine ao pensamento epidemiológico. Memórias do Instituto Oswaldo

Cruz, v.13, n.1, p.7-36, 1997.

SILVA, L.J. Organização do espaço e doença. In: Vários autores. Textos de apoio: epidemiologia 1. Rio de Janeiro: PEC/ENSP/ABRASCO, 1985. p.159-85.

SILVA, L.S Considerações acerca dos fundamentos teóricos da explicação em epidemiologia. Rev. Saúde

Púb., v.19, n.2, p.337-383, 1985.

STAMBOLOVIC, V. Medical heresy. The view of a heretic. Soci. Science Med., v.43, n.5, p.601-604, 1996.

VELOSO, C. O homem velho. Velô (disco) Caetano Veloso. Rio de Janeiro: Philips/33rpm, stereo, 1984.

WATERS, W.E. Epidemilogy in health care planning. Intern. Journal Epid., v.8, n.3, p.199-200, 1979.

PERINI, E. et al. , El individuo y lo colectivo - algunos desafíos de la Epidemiología y de la Medicina Social. Interface _ Comunic, Saúde, Educ, v.5, n.8, p.101-18, 2001.

Algunos de los conceptos fundamentales de la Epidemiología son revisados, explorando contraposiciones de sus principales contradicciones filosóficas. En este sentido, se discute la interdependencia conceptual entre el individuo y lo colectivo, la complementariedad de los abordajes cuantitativas y cualitativas, el carácter natural y social de la existencia humana y, en fin, las expresiones colectiva y individual del riesgo. Del a análisis se ha concluido que el concepto de riesgo trae en sí potencial para una revisión de la práctica epidemiológica. Sin escapar de los límites que la ciencia establece a la produción del conocimiento, esta revisión se ha propuesto a partir de la práctica de la confluencia de los métodos cuantitativo y cualitativo de investigación, más cercana de las necesidades inmediatas de los indivíduos. Sus posibilidades de concurrir para tornar más eficientes las acciones de la Medicina Social se amplían conforme el conocimiento de la realidad colectiva gana sentido para ellos.

PALABRAS-CLAVE: Epidemiología; Medicina Social; riesgo.

Recebido para publicação em: 10/04/99. Aprovado para publicação em: 22/10/00.

118 Interface - Comunic, Saúde, Educ 8

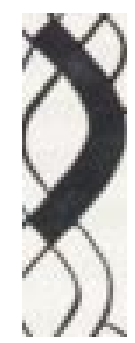

